\begin{tabular}{lllr} 
Hurricane & Total Number & Most Frequent Dx & \% \\
Hugo & Approx 300 & Soft tissue injury & 5.6 \\
& & Misc. medical & 50.7 \\
& & Eye, ear, nose, throat & 4.5 \\
Andrew & \multirow{2}{*}{668} & Medication refill & 12.9 \\
& & URI/OM/bronchitis & 11.8 \\
& \multirow{3}{*}{399} & Lacerations & 10.9 \\
Iniki & \multirow{2}{*}{39} & Tetanus immunizations & 20.1 \\
& & URI/OM/bronchitis & 18.5 \\
& & Lacerations & 9.3
\end{tabular}

Outreach Programs-The outreach programs came into existence during Hurricane Andrew. The Perrine Outreach Program evaluated 514 patients. During Hurricane Iniki, 54 patients were seen at the Kalaheo Outreach. For both of these outreach programs, tetanus immunizations led the list of required care followed by hypertension blood pressure checks and medication refills $(83.3 \%, 34.0 \%$, and $18.0 \%$, respectively). In contrast, strains, sprains, abrasions, and contusions accounted for $1.9 \%$ and $4.1 \%$ of the total number of outreach patients evaluated.

\begin{tabular}{|c|c|c|c|}
\hline Hurricane & $\begin{array}{l}\text { No. Patients } \\
\text { Evaluated }\end{array}$ & Most Frequent Dx & $\%$ Total Pts \\
\hline \multirow[t]{3}{*}{ Andrew } & 514 & Tetanus immunizations & 31.4 \\
\hline & & Medication refill & 12.4 \\
\hline & & HTN/BP check & 13.6 \\
\hline \multirow[t]{3}{*}{ Iniki } & 54 & Tetanus immunizations & 51.9 \\
\hline & & HTN/BP check & 20.4 \\
\hline & & Medication refill & 5.6 \\
\hline
\end{tabular}

Triage information-By far the greatest patient numbers were classified into the Green Triage category with a combined total of 886 patients for both Andrew and Iniki. By comparison, for the same two hurricanes, 38 patients were classified into the Red Triage category.

\begin{tabular}{lccc} 
& \multicolumn{2}{c}{ TRIAGE CATEGORY } \\
Hurricane & Green & Yellow & Red \\
Andrew & 507 & 128 & 32 \\
Iniki & 379 & 14 & 6
\end{tabular}

Comparative Costs-Hurricane Andrew, at a cost of [US] $\$ 20$ billion was the most costly. Accounts for Hurricane Hugo totaled $\$ 6.3$ billion, and Iniki cost $\$ 1.8$ billion.

Summary: Hurricane Hugo struck St. Croix on 18 September 1989. The 70-member DMAT team was activated on 28 September 1989 and remained on the island for 11 days. During that time, approximately 300 patients were seen. Hurricane Andrew touched down in Florida on 24 August 1992. A 71member DMAT team was deployed on 27 August 1992 for a total of 10 days. A total of 1,182 patients were evaluated (includes those by the outreach program). Hurricane Iniki struck the Hawaiian Islands on 11 September 1992. A smaller DMAT team, consisting of 47 members, was deployed on 19 September 1992 and remained for eight days. A total of 453 patients were evaluated (including those contacted by the outreach program).

\section{Development of a Disaster Emergency Medical Services (DEMS) Rotation at an Emergency Medicine Residency}

David E. Hogan, DO

University of Oklahoma Health Sciences Center

Emergency Medicine Residency Program.

This system is designed to introduce the resident to the field of Disaster Emergency Medical Services (DEMS), providing basic skills in disaster required for emergency medicine and exposure to other aspects of this growing field.

Methods: The Instructional Systems Design approach was used to create the disaster rotation. A brief educational survey was taken to judge the basic DEMS knowledge of the residents. A nominal group technique was used to arrive at a core content for the one-month rotation stressing the elements of DEMS thought to be most useful for the practicing emergency physician. A self-paced, programmed educational module was developed with individual goals and objectives for each content section. Two mentor discussion sessions are carried-out during the rotation for evaluation.

Results: Residents enrolled in the rotation have completed the requirements in an efficient manner. Several residents have extended participation in the rotation beyond the basic requirements to include research .

Conclusions: Development of a formal DEMS rotation in the framework of an Emergency Medicine Residency Program can serve to introduce residents to DEMS and strengthen local DEMS programs.

\section{Requirements for Hazardous Materials Incidents: A Statewide Plan}

Steven M. Joyce, MD, FACEP, Deborah H. Kim, MSN, RN, CEN, Jefferey G. Rylee, $E M T$

University of Oklahoma Health Sciences Center

Purpose: Conflicting information from a number of federal and state agencies has led to a lack of uniform statewide standards for hazardous materials operating materials operating procedures, equipment, and training. An ad hoc committee consisting of emergency medical services (EMS) physicians and nurses, EMS hazardous materials experts, and state emergency planners addressed this problem.

Methods: The committee drew on sources including but not limited to: 1) OSHA Hazwoper 1910.120 ruling, the Superfund Amendment Title III, HHS publications "Managing Hazardous Materials Incidents," Volumes 1 and 2, NFPA Document No. 3473, and documents related to the chemical weapons stockpile elimination's program (CSEPP). The committee than formulated a curriculum, operational standards, and equipment list that were both practical and affordable.

Results: The finished document addresses: 1) definition of hazardous materials; 2) classification of hazardous materials; 3) operating procedures for emergency medical services (EMS) and emergency department (ED) providers (analyzing the incident, planning and implementing the response, and terminating the incident) ; 4) a training curriculum for both groups; 5) a list of referenced publications; 6) recommended equipment lists (for personal protective equipment, decontamination equipment and facilities); 7) a respiratory program checklist (including fit-testing); 8) exposure logs; 9) guidelines for 
heat stress monitoring; and 10) a sample EMS hazardous materials protocol. All equipment and supplies were selected to be easily obtainable from local commercial sources that are specified. The document will be distributed for public comment, following which funding sources will be identified and the program will be implemented by the state.

Conclusions: A document detailing minimum curriculum, operating procedures, and equipment for response to hazardous materials incidents by EMS and emergency department providers has been developed for statewide use.

\section{A Comparison of Infusion Rates of Three Different Infusion Techniques Commonly Used by EMS Personnel}

Jeffrey Keifer, $M D$, Juan March, MD, Kathleen Dunn, $M D$, Lawrence Brown, EMT-P

Division of Emergency Medical Services,

East Carolina University

Purpose: To determine the efficacy of using a standard sphygmomanometer to increase the rate of fluid delivery. Volume replacement with rapid infusion currently is recommended for resuscitation of trauma victims. In the field setting, it is not uncommon to increase the rate of fluid delivery by inflating a sphygmomanometer wrapped around a plastic bag of fluid.

Method: Rate of flow was determined using a $1000 \mathrm{ml}$ plastic bag of normal saline placed at a height of $211 \mathrm{~cm}$ and infused through a standard, large gauge intravenous (IV) tubing with a 14-gauge catheter and vascular resistance assumed to be constant and minimal. Time to delivery of $250 \mathrm{ml}, 500 \mathrm{ml}$, and $750 \mathrm{ml}$ were measured, using only gravity as the control. The study was repeated five times and an average flowrate $(\mathrm{ml} / \mathrm{min})$. In addition, these same measurements were performed using a sphygmomanometer wrapped around the fluid infusion bag and inflated to $300 \mathrm{mmHg}$. The study also was repeated using a commercially available pneumatic pressure bag specifically designed for increasing infusion rates. Flow rate was compared by method and by volume group using analysis of variance (ANOVA).

Results: Mean flow rates \pm standard deviation $(\mathrm{ml} / \mathrm{min})$ Volume from bag $1-250 \mathrm{ml} \quad 251-500 \mathrm{ml} \quad 501-750 \mathrm{ml} p$-value

$\begin{array}{lcccc}\text { Control } & 146 \pm 2 & 140 \pm 6 & 139 \pm 11 & 0.32 \\ \text { BP cuff } & 264 \pm 13 & 156 \pm 4 & 139 \pm 7 & 0.0001 \\ \text { Infuser } & 352 \pm 4 & 245 \pm 6 & 173 \pm 2 & 0.0001\end{array}$

$\begin{array}{llll}p \text {-value } & 0.0001 & 0.0001 & 0.0001\end{array}$

Conclusion: During a resuscitation, a sphygmomanometer can be used to increase flow rates. Intermittent inflation is recommended to maintain maximal flow rate.

\section{Disaster Medicine Fellowship Training}

Clark A. Morres, $M D$

Madigan Army Medical Center

Purpose: To describe a new training program in Disaster Medicine at a military medical center.

Background: United States military involvement in recent disasters worldwide seems certain to continue. Recognizing the important role emergency medicine physicians play in these deployments, we developed a formal training program in Disaster Medicine.

Methods: Madigan Army Medical Center developed a 2-year fellowship in Disaster Medicine in 1993. The curriculum includes completion of didactic training in emergency management, incident command, nuclear and chemical accident management, critical incident stress debriefing, and HAZMAT. Clinical rotations include tropical and preventive medicine, and EMS. The fellow must complete the MPH degree with a disaster epidemiology research project. Field experience is gained in deployments as the commander of a multi-role military disaster response team, and through support to an urban search and rescue task force. Additional first-hand experience is obtained in operational assignments.

Conclusion: Madigan Army Medical Center's Disaster Medicine Fellowship will prepare physicians for military disaster relief missions worldwide.

\section{Emergency Medical Outreach into Communities Following a Disaster: Lessons Learned}

Clark A Morres, MD, Patricia R. Hastings, $M D$

Madigan Army Medical Center

Purpose: To highlight important considerations that will make community outreach successful when delivering medical care during disasters.

Methods: A retrospective analysis of: 1) debriefing records; and 2) after-action reviews of two physicians who provided medical care in a community outreach program one week after the Los Angeles, Calif,, earthquake.

Results: Outreach programs into communities affected by a disaster consist of health professionals providing medical care to victims who are homebound or otherwise unable to seek care. Heath-care providers, such as nonlocal Disaster Medical Assistance Team (DMAT) members, walk from door-to-door, or drive in small teams to see patients isolated by the disaster. This approach offers many potential benefits, particularly when the local infrastructure has been diminished.

Several factors identified in an outreach effort after the Los Angeles earthquake (1994), should be considered when planning disaster outreach missions: 1) clear objectives and limits for the outreach effort must be established; 2) the safety and security of the medical teams and their equipment must be assured to the greatest degree possible; 3) a means of communication must be available; 4) a geographic orientation must be given to each medical team defining the boundaries of the outreach and the planned routes in and out of the area; 5) medical kits should be prepared in accordance with the specific mission objectives; 6 ) a variety of medical contingencies must be anticipated; and 7) plans must be made to provide for urgent evacuation, nonurgent referral, and follow-up care of patients.

Conclusions: Consideration of several important factors will make community outreach a safe and successful medical delivery approach during disasters. 